or by any other supposition at all in harmony with the view that paralysis in brain disease depends on loss of the function of the part visibly altered. In presence also of the following featuresthat a paralysis of the arm will exist alone, or appear first, or be more intense or more persi-ting than a paralysis of the leg, in a large proportion of cases of disease of the brain, without any possibility of explanation in harmony with the hypothesis that paralysis in organic cerebral affections depends on loss of the function of the part duseased,-I do not think we can avoid rejecting absolutely that hypothesis.

I now pass to another series of arguments, the main object of which is, however, to show also that we ought to reject as completely groundless and false the still generally admitted view that paralysis in cases of diseases of the brain arises from the loss of the function of the part visibly altered in that organ. The history of facial paralysis in brain disease, which is now the subject I am to examine, is extremely rich in facts speaking loudly against the admitted views. Long ago (in 1861), in my Gulstonian Lectures, delivered at this College, I insisted on several arguments relating to facial paralysis, and showing that these views were contrary to fact. On the one hand, I showed that a few facial muscles only are usually paralysed in diseases of other parts of the brain tban the pons Varolii, and on the other hand I showed also that this narrowly limited paralysis was found sometimes or frequently in cases of disease in any part of the cerebral hemispheres, including the sensory-motor ganglia and the base above or in front of the pons. In presence of such facts it was clear that admitting that facial paralysis depends on loss of the func. tion of the parts diseased was coequal to admitting that the motor nerve-fibres going to the few facial muscles so frequently paralysed in brain disease were all present in each part of the brain, or that in one individual they are in one part and in another person in another part-two sup. positions too absurd to be for one moment accepted. I will now lay before you man $\$$ series of facts which will, I hope, be, if possible, more able than my previous arguments to prove that we must give up the admitted views.

The first pnint on which I will insist is that faciai paralysis can be caused by brain disease without hemiplegia or paralysis of limbs. A case well wortby to be mentioned first is that of an eminent surgeon, Dupuytren, who himself was attacked with paralysis limited to the face from a cerebral hæmorxhage. He was leuturing at the Hôtel Dieu in Paris when attacked. His mind not being affected, he had the courage to proceed with bis lecture, bolding his face with his hand. He lived nearly fifteen months after the attack, and died of pleurisy. The autopsy revealed as the cause of the slight apoplectic attacks he encountered, and the only cause of the facial paralysis, the remnants of several old effusions of blood in both corpora striata and in the right optic thalamus. ${ }^{7}$ In a remarkable case, carefully recorded by Duplay ${ }^{8}$, the face was suddenly paralysed, the loss of voluntary action showing itself in all the muscles animated by the left facial nerve. There was no other paralysis. Recovery took place within a year without treatment. Death occurred twenty months after the para. lytic attack, and an old and small apoplectic cyst containing serum was found in the right corpus striatum. The pons Varolii, the medulla oblongata, and the left facial nerve were perfectly healtby. This case is of great value in showing not only that a paralysis limited to the face can be caused by an organic disease in another part of the brain than the place of crigin of the facial nerve, but also that the kind of paralysis which is usually the effect of disease of the facial nerve in and out of the pons Varolii can be caused by disease in other parts of the brain. This last point will be established by other facts by-and-by. I will now proceed to show that what we have seen already as regards paralysis limited to one arm or to one leg is seen also as regards paralysis limited to the face-namely, that the loss of voluntary movement can appear on the side of the lesion or on the opposite side.

7 See Gazette Médicale de Paris, 1837, p. 111; and Journal Hebdomad. de Médecine, 1845, vol. 1, p. 213.

8 De la Paralyile Faciale produite par une Hémorrhagie Cérébrale (Paris, 1854), p. 9. A reprint trom the Union Médicale, Aôt, 1854

EARL Spencer has been re-elected President of the Royal Victoria Dispensary, Northampton, for the ensuing year.

\section{THE HISTORY OF A CASE OF BURST OVARTAN CYST.}

\section{Bx THOMAS KEITH, M.D. EdIN.}

Is a paper published two years ago in the Edinburgh Medical Journal, I endeavoured from a number of cases to show that, however hopeless-looking the circumstances, operation ought to be the rule of practice whenever there is acute suppuration in an ovarian cyst, or when typhoid symptoms come on after rupture or tapping. The following narrative affords an instructive illustration that this principle is a sound one.

A young married Englishwoman came to me from Dr. Gowans, of South Shields, in the end of October last. The local conditions seemed favourable, though the general condition was perhaps a little too good for operation, at least better than I like to have to do with. The tumour had grown rapidly. It filled the abdomen, and pushed the ensiform cartilage upwards. The measurement was already forty-three inches, and there was commencing cedema of the abdominal wall and lower limbs. The cyst was extremely tense, and fine friction was unusually distinct almost all over its surface. There was obscure fluctuation on the left side, but the tumour on the whole felt semisolid. Atta ks of pain were frequent and severe, and she was of ten sick. On account of the tension, which was unusual, and not safe in the case of a tumour that had grown. so rapidly, operation would have been performed on the day after her arrival, had not the period come on with violence a fer days before it was due. When this passed off, the patient went out for a walk on a very cold day, lost her way in the streets, and came back fatigued and ebilled. Fur several days after she had slight shiverings, looked ill, and became very sallow. She got daily into a less good state for operation; she was feeble, listless, and lay about. There was a little albumen in the urine and a trace of bile, but increase of tension was so rapid that delay was more dangerous than waiting for the chance of improvement. Operation was fixed on for Nov. 4th.

On placing my hand on the abdomen, in the morning, to. feel the friction-sound once more, both friction and tension had disappeared, and there was clear sound under the ensiform cartilage, where none existed the night before. It was evident that some leakage was going on from the tumour somewhere. An hour afterwards, at the time for operation, Dr. Growans was present from Shields, and there were some German and other visitors. By this time rupture of some cyst was more decided, and there was a slight wave of fluid over the upper part of the tumour. On putting an aspirator needle into the softest part above the umbilicus, about a pint of thick black fluid, like hare-soup, was with difficulty got away. On withdrawing the needle, which got plugged with a piece of lymph, some fluid from the peritoneum spirted up in a fine stream through the needle punca ture. This was thinner than that from the cyst, though almost as dark in colour. It was afterwards found, when the deposits of these two fluids had subsided, that that from the cyst gave a sediment of old clot and fibrin amounting to nearly one-half, while the fluid from the peritoneal cavity showed only one-twentieth, of a soft, pinkish, purulent-looking character. There could be no doubt that the rupture was a small one, and that the fluid was being slowly filiered through old blood-clot.

The question now arose whether operation should be gone on with or not. There was no constitutional disturbance, no pain, no tenderness. There is nothing in ovariotomy $I$ more dread than to find a fluid containing old blood in the abdominal cavity. However carefully this nay be cleaned, experience had long ago taught me that in such circum. stances there is risk of septic peritonitis. Here it was certain that within an hour or two a quantity of the worst kind of fluid bad escaped upon a fresh peritoneal surface. It was a choice of evils. I decided to wait. Not much more fluid could escape, for the tumour was mostly semi-solid. The fluid might be absorbed, as I bad often seen happen before, and operation might be performed in a week or twa with a better chance of success. Present relief of tension 
had so tar bren obtained hy the removal of thirty ounces of fluid. Opera'ion must be more than usually haztrdous in the case of a parient whose liver was congested, whose kidneys were eliminating but little, and that little containing both bile and albumen. The day was pasied quietly without complaint. The action of the skin was solicted in vain. By evening the skin was hot and dry. 'I'emperature $101^{\circ}$; pulse 120. The night was good, but next day the pu'se and temperature continued to rise, and thirty bour after the rupture the temperature in the axilla was $106^{\circ}$, in the mouth $105 \cdot 6^{\circ}$; pulse 130 ; respiration 32

Third day-Night restless; aspect bad; severe bilious vomiting. Temperature $1045^{\circ}$; pulse 120 . Vomiting continued during the day; skin hot and dry; face, hands, and limbs swollen; abdomen softer; flatus passing; no pain.

Fourth day.-Temperature $103.5^{\circ}$; pulse 120 . Much thirst and restlessuess ; flatus coming up in quantity ; dark red fluid voruit d all day.

Fifth dig.-Temperature 103.8 ; pulse 130. Vomiling almost crnstant since 3 A M.; looks pinched and ill; distinctly jaundiced all over; slight tendeney to diarrhce free stimulatiın all day. By evening she was easier, and had slept, and bad retilined a little soup. On account of the relaxed state of the sphincter neither nutritive nor stimulat ing enemita can he retained five minutes. The urine is scanty, lodder wi h hile, yiving also a deposit of one-tenth of albumen, with a $f \in w$ renal cells. Now all evidence of free fluid in the ahdomen has disappeared, though there seems to be some in $D$ uglas's space. 'T'here is much gener; soft swelling in the pelvis; the cervix is much swollen; th uterus is low down, is moved forwards towards the pubes, and somew hat fixed.

The sixth, seventh, and eighth days were spent mostly in vomi ing, while some rust was got at night by opiates. 'The typhoid sympt ms became more marked, the tongue was dry, teeth and lins black. skin harsh and dry. Temperature ranged from $102^{\circ}$ to $105^{\circ}$; pulse from 110 to 125 . There nev+r was pa'n or tenderness anywhere.

On the nin $h$ day the tumour at the epigastrium was again tense. T'wenty ounces of thick, blo dy fluid were got away by an aspirator. Tension was some what relieved, and the day was passed quietly without vomiting. Next day the vomiting returned, with increase of fever and acute swelling of the right foot and leg. When seen late at night there was a small spot near the umbilicus which gave a tym panitic sound; this could only arise from air in the cyst. No more favourable time could now be looked for.

Next morning, November 15 th, things had in no way im proved. The night was not bad, though there was some vomiting towards morning. Temperature $1035^{\circ}$; pulse 122. very feeble. The abdomen was now more generally distended, the area of tympanitic sound at the umbilicus was greater, while here and there all over the tumour there was obscure resonance on deep percussion. Decomposition was going on in the tumour, and air was being rapidly secreted. The prospect was not a hopeful one, and though I had several times operated in nearly similar conditions, this patient seemed to have absorbed more poison than any of the other cases of putrid cyst. 'The temperature was higber than in anyone, so far as I knew, on whom ovariotomy had been successfully performed, while the severe vomiting of the last ten days had greatly reduced her strength. Sbe seemed to have shrunk to half her former size. Then she was jaundiced and had phlegmasia dolens; the ekin was harsh and hot, the kidneys acting very little, and the tnngue and mouth so dry that articula. tion was difficult. With all this she was strangely indifferent and unconcerned as to her fate.

Sulphuric ether was given by Dr. Foulis, and I had the assistance of Dr. Sidey and Dr. McGibbon, friends always ready to come to $m y$ help at any moment, at whatever inconvenience to themselves. Dr. Church was the only visitor present. A layer of soft thick recent ly $\mathrm{mph}$ covered the tumour. The hand passed through this easily in all directions except above and posteriorly, where old and firm adbesions to the omentum, mesentery, and intestines existed. On putting in the trocar there was a rush of putrid air filling the room with its gangrenous odour. Little fluid came away. The band was passed into the tumuur, and a quantity of putrid blood-clot and fibrine removed. The rest was semi-solid and was slowly broken down. The whole was putrid, and the cyst-walls-as tender as blotting-paperwonld not bear any pull upon them. All fluid was thelefore pumped out. Adhering to the under surface of the liver, the cyst was very thin, black, and gangrenous. The omentum was adherent to the tumour and wall; posterinrly, firm and extensive adhesions to mesentery and intestines were separated; these were all matted together by recent lymph. Just as the cyst-walls were almost all turned out of the abdomen, and as some loose adhesion near the brim of the pelvis was being separated, and while I was congratulating myself that such a friable and putrid mass of cysts was got away without tearing or escape of infective fluids over the contents of the abdomen, there came a sudden gush of horribly fetid fluid from below, splashing over everything. It was now seen that an encysted collection in the pelvis, roofed over by the base of the tumour, had been opened into. The pelvis and its contents, uterus, and rectum, were coated with a thick lining of intensely putrid lymph. This could be peeled off in layers, leaving a raw bleeding surface. All fluid was eponged up, quantities of soft fetid lymph removed from the bottom of the pelvis, the whole of Douglas's space washed again and again with a solution of carbolic acid ( 1 in 20 ), and a warm solution of the same was freely sponged over the whole upper pelvis and wound, and whrever the putrid fluid was thought to have reached. Most of the small intestines, being adherent high up, had fortunately escaped contact with the fluid from the pelvis. Lister's ligatures were applied to all bleeding points, the torn omentum tied in five portions, many patches of thick soft lymph adhering here and there in all directions were removed (though it was bopeless to try to get them all away), the usual glass drainage-tube was put in above the clamp, and the wound closed by silk sutures. The putrid mass and cyst contents weighed twenty-five pounds.

The operation lasted an hour and a half. She was placed in a warm bed, and brandy and opium injected into the rectum. Two hours after, at 230 P M., four ounces of very bloody serum were removed from the tube (this fluid was quite sweet); at 4.30 one ounce, at 9 P.M. half an ounce, and at 11 P M. half an ounce. At 9 P.M. the temperature was $1036^{\circ}$; pulse 130 ; respiration 28 . She bad romited twice. There was now eopious perspiration about the head and neck. She looked pale and ill, but was cheerful. At 11 she was again violentiy sick, romiting green fluid. At midnight there was a copious perspiration; temperature $103.4^{\circ}$; pnlse 140. At 2 A.m. barely half an ounce of fluid in the pelvis.

Nov. 17th.-Temperature $103.6^{\circ}$; pulse 130 . Only fonr ounces of urine, loaded with pink lithates. Tongue dry and furred. During the day had short sleeps and occasional perspiration. Red serum removed from time to time. Towards evening romiting became severe, large quantities of matter like chopped grass being thrown up; œedema of right leg almost gone, that of the left wholly so. During the day, fourteen ounces of urine loaded with lithates; temperature $1035^{\circ}$; pulse 124.

18th.- Restless night. Vomited at 5 A M. ; looks tired and ill; tongue so dry and tremulous that ske can scarcely speak. Temperature $1033^{\circ}$; pulse 118 . Urine passed involuntarily; abdomen distended and hard. One ounce and a half of red serum from pelvis. Towards afternoon fell into a sound sleep, and there was copious perspiration; the skin became soft, the tongue less dry, and flatus passed freely. Three ounces of nearly clear serum were removed at different times from the pelvis during the day. Bg evening the temperature had fallen three degrees. The improvement was sudden and remarkable.

19th. - Temperature fell other three degrees during the night, six degrees in twenty-four hours, and is now $978^{\circ}$; pulse 88. Two ounces and a half of turbid serum from tube, not fetid.

For the next week there was slow but steady improvement. Then she fell back again, and the pulse and temperature were rarely under 100 . The wound, which for a week seemed bealed, gradually opened up, and closed by granulation. Though she took food pretty well, she lost flesh, and every now and then, almost every day sometime, there was vomiting of bile. Some swelling, with obscure feeling of fluctuation, formed to the left of the umbilicus, where adhesions were greatest, and where there was most matting of the iutestine. There was also general tym- 
panites. On the twenty-eighth day after operation there was severe vomiting. By evening she was almost collapsed, with rapid and nearly imperceptible pulse. The swelling had entirely disappeared. There must have been some limited collection of fluid which had found its was into the cavity of the abdomen. Very free stimulation was again necessary. For two whole days the basin was not away from under her mouth, and there was a repetition of the condition that caused such anxiety four weeks before. After several days of drenching perspirations, convalescence went on satisfactorily. She returned to Shields a few days ago (Jan. 4th).

The appearances this abdomen presented at the operation were such as are not seen except at a post-mortem examination. Most remarkable was the condition of the pelvic cellular tissue. Felt from below, immediately before operation, beyond a general fulness and softness of the vagina, there was nothing unusual. The uterus, which a week before was somewhat fixed, was now fairly movable. The cervix was still large, but there was no tenderness or hardness anywhere. Yet, when looked at from above, the swelling of the pelvic soft parts was such that three fingers only could be pushed into the cavity, instead of the whole hand with a big sponge in it, as is usual.

In my former cases of acute suppurating or putrid cysts, with high temperature, there was a fall of temperature immediately after operation. In this patient the temperature did not fall, neither was there any improvement in the general condition till forty-eight hours after.

I have only once before met with a case of gangrene of the cyst. ${ }^{1} \quad \Delta \mathrm{s}$ in this patient, there was a chill, and tapping was performed to relieve pain and $t+n s i o n$. Typhoid symptoms rapidly came on, and ovariotomy was performed in the semi-delirium of septic fever. In another case, ${ }^{2}$ a large acute suppurating cyst had burst into the abdomen. During ovariotomy, three weeks afterwards, an encysted collection was found in the pelvis. This cavity was lined with a thick layer of lymph, which could easily be peeled off, and was filled with pus of the consistence of soft butter, evidently the deposit of the large quantity of purulent fluid which had escaped, and which nature was unable to dispose of in any other way than by encysting it. In another case, where a suppurating cyst had also burst, tapping was performed a few hours after the rupture, the patient being then almost pulseless. Here no collection was found in the pelvis at ovariotomy three weeks after; there was only firm posterior adbesion about the sacrum, to the uterus, rectum, and pelvis generally. Recovery took place in these three in. stances.

$I$ have now operated fourteen times in cases of acnte suppurating or putrid cysts. ${ }^{3}$ Every one at the time looked hopelessly bad, yet twelve of them recovered. If in such a proportion bad cases do well, surely the mortality after ordinary operations of ovariotomy ought to be much lower than it is. Yet, speaking for myself, the mortality year by year diminishes. In the last 107 operations there have been 10 deaths, while of 21 performed last year all got well save one. Edinburgh.

\section{A CASE OF}

\section{LOCALISED INJURY OF THE ANTERIOR CONVOLUTIONS OF THE BRAIN, WITH PECULIAR SYMPTOMS.}

\section{By A. D A V I D O N, M.D.,}

PHIYSTCYAN TO THA LIVERPOOL ROYAL INFIRMARX.

Great addition has been made in late years to our knowledge of the functions of the various parts of the brain, chiefly through experimentation on the lower animals. It seems to me that still more might be learned in this department of physiology from carefully observing and recording the symptoms in the cases of limited lesions of the human brain from accidental injuries, which must frequently come under observation in the surgical wards of

1 The Lancer, 1865, p. 480. 2 Edin. Med. Jour., Feb., 1875. 3 Edin. Med. Jour., 1875. our hospitals. The following case is a small contribution of this kind. The patient was admitted into the surgical wards of the Liverpool Northern Hospital. I had the opportunity of seeing him and observing his symptoms, and I have received the permission of Dr. Grabam, the surgeon under whose care he came, to publish the case.

Patrick M- aged thirty years, a labourer, was working outside a cotton warehouse on the afternoon of June 10th 1875, when a large iron hook, used for hoisting bales of cotton, which was suspended by an iron chain to the topmost storey of the warehouse, swung against his head, and carried away a considerable piece of the skull, leaving a great gaping wound, through which the injured brain-sub. stance protruded. He was at once carried to the hospital. When in the accident-room he was found to be apparently conscious, though his manner was peculiar. He understood the questions put to him, and gave his name and address when asked. He was taken up to bed. I saw him within half an bour after his admission. There was an extensive wound of the scalp, which.was retracted, exposing a great opening in the frontal skull, chiefly on the right side, from which blood was oozing freely, and through which injured convolutions of the brain could be seen. The injury on the right side extended as far back as the coronal suture or a little behind it-that is, as far back as the posterior part of the superior frontal convolution. There was a considerable piece of half-loose bone here, pressure on which caused som pain. On the left side the deficiency of bone did not extend so far back by about an inch. Here, too, there was a loose piece of bone, about the size of a penny, driven down and fixed firmly on the surface of the brain about the middle part of the superior frontal convolution of that side. There was evidently much more injury and destruction of brainsubstance on the right side than on the left.

I found the patient at this time, within an hour of the injury, in a very peculiar condition. He had just lain down in bed. His pulse was 70, of fair strength. There was no collapso. He put out his tongue when asked, and gave his name and address. He volunteered no remarks. When asked how the accident happened, he answered vaguely "he was going to have some tea with this young woman" (pointing to one of the nurses). He showed himself rather restless, sitting up in bed occasionally. While the nurses were sponging the blood from his arm, he assisted them by holding the arm out and turning it round, and occasionally pointed to spots which he wished to be cleaned, but with. out speaking. $\mathrm{He}$ also frequently wiped away with some tow the blood which trickled down his face from the scalp wound. He appeared to suffer no pain, nor to have any idea of what had happened to him. He swallowed some milk, and ate some bread which was given to him. He did this not as if he was hungry, but merely because it was given to him. Indeed, every action he performed left the impression on the mind of the observer that it was purely automatic. On two occasions only did be say anything, except in answer to questions, and then the remarks appeared to be delirious, and to have reference to the work he had been engaged in- "Bill, shove that out of the way," \&c. One striking fact was that, after the nurses had ceased to sponge away the blood-stains on his arms, he still held out his right arm of ten in a spasmodic way, stretching it out suddenly and violently, and pointing out spots. He also frequently sought to shake hands with those near him, go of ten as to be quite ludicrous. He did not attempt to get out of bed. No paralysis of face, arms, or legs could be detected. He opened his eyes when asked, and could move them about in every direction. After a short time he lay down and remained quiet. When $\mathrm{I}$ saw him again two hours later he was in a similar state, but quiet. Dr. Graham also saw him, and ordered ice to be applied to the brain in a bag.

June 11th.-Next day he was in a similar state, but still quieter. Pulse as before; temperature normal; no paralysis. $\mathrm{He}$ made water naturally in the nigbt; he got ont of bed and stood on his feet, and the night nurse, seeing what he wanted, brought him the urensil, which he used. To.day his bowels acted involuntarily in bed. Durmg the course of the day he lay quiet, but shook hands with ancona who came near his right hand. He never spoke except t) say once or twice, "Ob, my head!" He showed no recognition of the circumstances he was placed in. Fie evidently did not like to be disturbed, and if anyone uncorered him he 